\title{
Effectiveness of Standardized Patient in Abdominal Physical Examination Education: A Randomized, Controlled Trial
}

Azita Jaberi, PhD and Marzieh Momennasab, PhD

Introduction: Simulation and virtual technologies currently are used to enhance basic and advanced nursing skills. Information on the use of simulation methods in the Iranian nursing education system, particularly regarding standardized patients (SP), is scarce. Hence, the present study aimed to evaluate the effect of using SP on the performance of Iranian nursing students in the physical examination of the abdomen. In addition, the SP method was compared with the purely lecture-based education method.

Methods: The present study was of a pre-test/post-test design carried out at the School of Nursing and Midwifery, Kazerun Islamic Azad University (Kazerun, Iran) during 20I4. Third-year nursing students were recruited and assigned to either a control or an intervention group. The study was conducted in three phases: pre-test knowledge evaluation, training sessions, and post-test/recall test evaluation of objective structured clinical examination (OSCE). Data were analyzed using the SPSS software (version 16.0). A total of 87 students were included in our analysis.

Results: All participants were female with a mean age of $21.99 \pm 1.73$ years. The mean pre-test score of the control and intervention groups were $4.98 \pm 2.17$ and $5.35 \pm 1.77$, respectively. No significant difference was observed between the groups regarding the OSCE overall scores $(P>0.05)$. However, there was a significant difference between the mean pre-test and post-test scores in each group $(P<0.05)$. Compared to the control group, the difference in the mean pre-test and post-test scores was higher in the intervention group (4.98 \pm 2.17 and $14.43 \pm 3.93$ in control group vs. $5.35 \pm 1.77$ and $15.39 \pm 3.2$ in intervention group, respectively). Furthermore, there was no statistically significant difference between the groups in terms of the post-test and recall test scores.

Conclusion: Our study demonstrates the SP method is an effective tool for learning to perform the physical examination of the abdomen as compared to the purely lecture-based educational method. The present pilot study could be extended to cover training on the physical examination of other human organs.

Keywords: Standardized patient; Abdominal physical examination; Nursing students

Corresponding Author: Dr. Marzieh Momennasab, Associate Professor of Nursing, Department of Nursing, School of Nursing and Midwifery, Shiraz University of Medical Sciences , Zand Street, Namazee Sq. Shiraz, Iran, Postal code: 71936-13119. Tel: +98(7I I)6474255-8, Fax:+987I36474252, Email: momennasab@sums.ac.ir
Received: June 13,2018

Ist revision: September 22, 2018

2nd revision: November 28,2018

3rd revision: February 3, 2019

4th revision: March 13,2019

Accepted: March 28, 2019

Disclosures: The authors disclose receipt of the financial support from the Vice-Chancellor for Research Affairs of Shiraz University of Medical Sciences, Iran, for the research of this article. The authors declare no potential conflicts of interest with respect to the research, authorship, and/or publication of this article. 
A ccurate health assessment of patients is the most important phase of nursing intervention. ${ }^{1,2}$ It allows the development of an effective medical plan, its implementation, evaluation, and evidence-based nursing care. ${ }^{3}$ In this context, nursing students must be given the opportunity to connect theory to practice, rehearse, and elevate their knowledge and skills. ${ }^{4}$ Physical health assessment skills are an integral part of any nursing degree program and recognized as the standard education and minimum required competence. $^{5}$ However, despite elaborate educational programs, these skills are not effectively put into practice. ${ }^{4,6-8}$ Traditional teaching methods are reported to be the main reason for such shortcoming. ${ }^{9}$

Regretfully, the Iranian nursing education program suffers from the shortcomings of lecture-based teaching methods. Typically, the program consists of a weekly lecture combined with video presentations on the physical examination (eg, inspection, palpation, auscultation, and percussion). Students are evaluated using the traditional written examination rather than objective structured clinical examination (OSCE). Following the theoretical sessions, practical experience is gained in live clinical settings and is limited to examining actual patients under the supervision of a hospital instructor. ${ }^{10}$ There are multiple disadvantages in a teaching method involving nursing students, instructors, and actual patients.
When inexperienced nursing students are exposed to live clinical settings, they lack self-confidence, are overwhelmed by fear, and may not even receive the required amount of time to practice. Additionally, instructors are overloaded and may not have the time or patience to pay attention to each student. And last but not least, uncooperative patients and the shortage of clinical facilities may further hinder educational goals. ${ }^{11-19}$ Subsequently, implementing alternative and innovative instructional strategies is deemed necessary for novice students, ${ }^{20}$ particularly in the area of communication, interpersonal skills, and reflexive skills. ${ }^{21}$

The use of technology-based teaching methods has gained momentum in nursing education. Simulation and virtual technologies are currently used to enhance basic and advanced nursing skills. ${ }^{22,23}$ Simulation methods, particularly the use of standardized patients (SP), could be the key components for adequately preparing nursing students to face the constantly changing clinical environment. ${ }^{24}$ The simulation-based learning method has been used to support the development of health assessment and therapeutic communication skills and to encourage decision-making and critical thinking. ${ }^{25} \mathrm{~A}$ SP is an individual who is adequately trained to imitate a patient's set of symptoms and provide verbal and written feedback to students. ${ }^{26-30}$ Since the 1960 s, SPs have been widely used in teaching programs for medical students $;{ }^{31}$ however, its use in

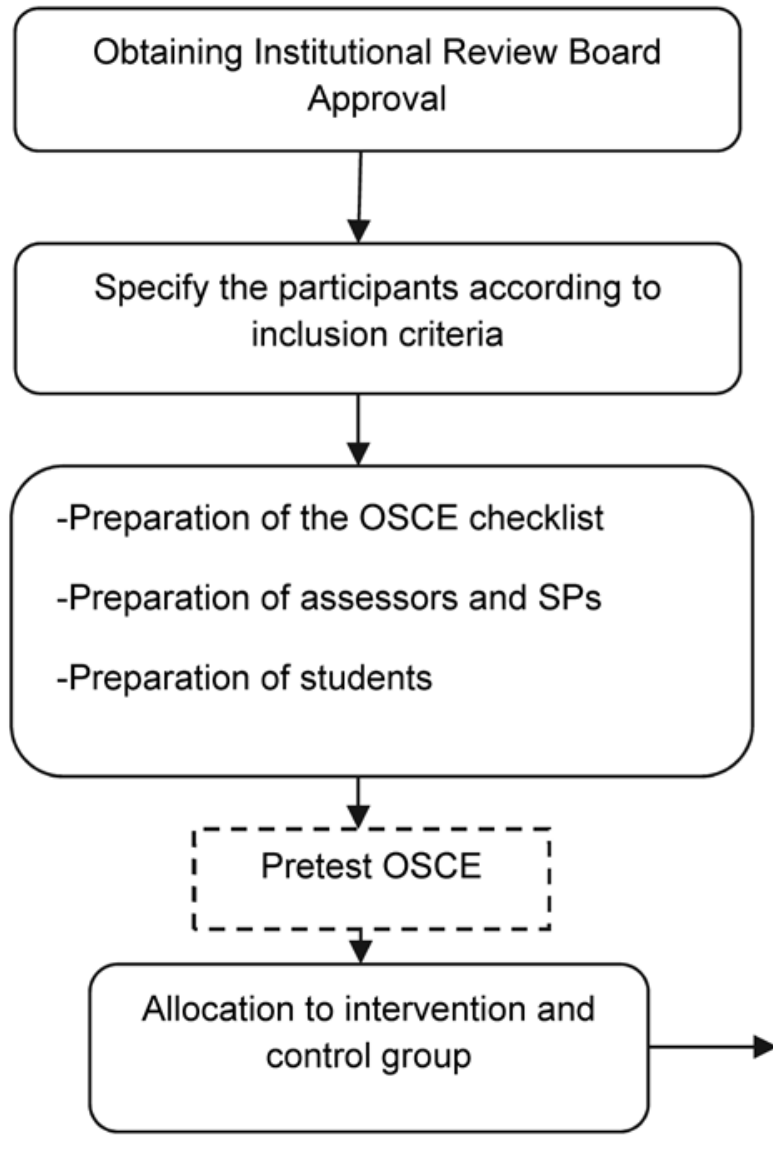

\section{Education of abdominal physical exam}

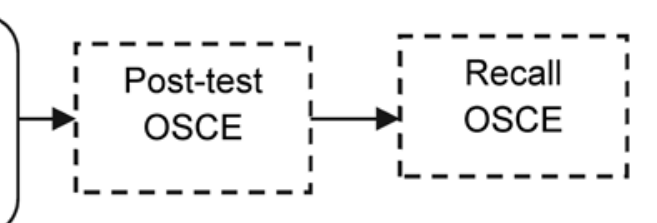

Figure 1. The study protocol. 
nursing education is not as widespread. ${ }^{32-34}$ The use of an SP simulator has beneficial effects on cognitive, affective, and psychomotor abilities, ${ }^{35,36}$ communication skills, ${ }^{37}$ learning motivation, satisfaction, and clinical competence. ${ }^{38,39}$ Yet, its greatest impact has been reported in the psychomotor domain, such as clinical competence. ${ }^{40}$

The use of SP has generated much interest among nursing instructors in reaction to the challenges of care complexity and the pressure from the health care system. ${ }^{41}$ Nonetheless, similar to some other countries, its deployment in Iran is very limited, despite reported advantages in clinical education. ${ }^{42}$ There are some reports on the use of OSCE and SP among Iranian medical students; ${ }^{43,44}$ however, Saboori et $\mathrm{al}^{43}$ challenged the use of SP by stating that it did not improve medical students' history-taking skills compared to traditional lecture-based education. Unfortunately, use of SP in the Iranian nursing education system also faces many challenges. In addition to the limited budget to support an SP simulation program, nursing education in Iran is influenced by traditional teaching methods, socio-economic and political factors, and cultural perception, values, and prejudices. ${ }^{45}$ These challenges restrict Iranian nursing students from elevating their knowledge and skills to the level of the internationally recognized Registered Nurse (RN) certification. Moreover, it is essential for them to become familiar with new methods of education and evaluation. ${ }^{46}$

Considering the above challenges, it is of no surprise that there are very limited studies in Iran on the use of SP in nursing education. As a direct result, the present study aimed to evaluate the effect of using SP on the performance of Iranian nursing students in the physical examination of the abdomen. In addition, the SP method was compared with the purely lecture-based education method.

\section{Materials and Methods}

The present study was of a pre-test/post-test design carried out at the School of Nursing and Midwifery, Kazerun Islamic Azad University (Kazerun, Iran) during 2014. The participants were selected based on a convenience sampling method among third-year students undertaking a course in physical health assessment. The sample size was determined at 128 participants (considering alpha $=0.05, \mathrm{~d}=05$, and power $=0.8$ ) to be equally divided into an intervention and control group. However, since there were only 91 third-year students available, the convenience sample method was used. The inclusion criteria were undertaking a course in physical health assessment and willingness to participate. The exclusion criteria were more than one absence from educational sessions and not participating in the OSCE test. Based on the inclusion criteria, a total of 91 participants were selected. The participants were randomly allocated to a control group $(n=46)$ and an intervention group $(n=45)$. Both groups received education on physical examination of the abdomen through lectures and video presentations; however, the intervention group additionally received training using the SP method.

The educational sessions (lectures and SP) and OSCE were carried out by three instructors and six assessors, respectively. Both the instructors and assessors were comprehensively trained by the author and two other members of the academic staff with extensive experience in physical examination. The instructors were trained for 4 hours on the physical examination of the abdomen 5 days prior to the pre-test. Similarly, the assessors were trained for 7 hours on the OSCE evaluation method, which included the OSCE process flow and how to evaluate each item on its checklist. An additional discussion session was held with both the instructors and assessors on the functioning of SP and the evaluation process.

The three individuals who acted as SPs were novice actors without any medical background. Their 15 hours of training to master the art of imitating a patient included explanations on the study goals, procedures, laboratory environment, signs and symptoms of abdominal disorders, verbal feedback to the students, and basic information on physical examination. These individuals were instructed to avoid unnecessary conversation with the students. Consolidation of these evaluations is illustrated in figure 1 .

\section{Procedure}

The main goal of the study was to compare the performance score on the physical examination of the abdomen between the control and intervention groups. Additionally, we aimed to determine the level of satisfaction with the SP experience among the students in the intervention group. Based on these goals, the study was conducted in three phases: pre-test knowledge evaluation of the students, training sessions, and post-test/recall test OSCE evaluations.

\section{Phase 1: Primary Knowledge Evaluation}

The pre-test level of the participants' knowledge was evaluated using the OSCE test. Initially, one week prior to the pre-test, students were provided with information about the study purposes, content, and procedure. After obtaining written informed consent, students were provided with the OSCE checklist on all physical assessment criteria they were expected to be able to demonstrate.

The OSCE consisted of six stations: one station on how to prepare a patient, four stations on abdominal examination (inspection, auscultation, palpation, and percussion), and one station on additional examinations (ascites, appendicitis, cholecystitis, and ballottement). Based on the available literature on physical examination, a checklist was developed for each station. ${ }^{47-51}$ The six stations of the OSCE included three SPs stations and three mannequin stations. The students attended each station for 3 minutes and performed the required tasks on the SP or mannequin while their performance was being evaluated by one assessor at each station. 
Table1. The two groups' mean scores of OSCE (pre-test, post-test, and recall test) before, immediately after, and two months after the intervention.

\begin{tabular}{|c|c|c|c|c|c|}
\hline & & lean (SD) & & & lue \\
\hline & Pre-test & Post-test & Recall test & $\begin{array}{l}\text { Within } \\
\text { subjects }\end{array}$ & $\begin{array}{l}\text { Between } \\
\text { subjects }\end{array}$ \\
\hline Preparation \& histo & & & & & \\
\hline Control & $1.08(1.8)$ & $1(0.36)$ & $1.21(0.23)$ & 0.000 & 1 \\
\hline Experimental & $1.1(0.18)$ & $0.94(0.41)$ & $1.31(0.21)$ & $<.001$ & \\
\hline Inspection & & & & & \\
\hline Control & $0(0)$ & $1.4(1.29)$ & $1.67(0.7)$ & 0.000 & 0.61 \\
\hline Experimental & $0(0)$ & $1.54(0.85)$ & $1.82(0.54)$ & & \\
\hline Auscultation & & & & & \\
\hline Control & $0.46(0.23)$ & $1.38(0.56)$ & $1.83(0.32)$ & 0.000 & 0.25 \\
\hline Experimental & $0.51(0.28)$ & $1.64(0.55)$ & $1.77(0.45)$ & & \\
\hline Palpation & & & & & \\
\hline Control & $1.05(1.02)$ & $2.96(1.16)$ & $2.03(0.9)$ & 0.000 & 0.68 \\
\hline Experimental & $1.1(1.00)$ & $2.56(1.13)$ & $2.09(1.03)$ & & \\
\hline Percussion & & & & & \\
\hline Control & $2.18(1.42)$ & $4.97(1.55)$ & $5.8(0.97)$ & 0.000 & 0.84 \\
\hline Experimental & $2.38(1.39)$ & $5.22(1.56)$ & $5.6(1.16)$ & & \\
\hline Addtional Examina & & & & & \\
\hline Control & $0.19(0.4)$ & $2.63(1.08)$ & $3.06(0.57)$ & 0.000 & 0.01 \\
\hline Experimental & $0.25(0.37)$ & $3.12(0.7)$ & $3.23(0.51)$ & & \\
\hline Total & & & & & \\
\hline Control & $4.98(2.17)$ & $14.43(3.93)$ & $15.59(2.21)$ & 0.000 & 0.41 \\
\hline Experimental & $5.35(1.77)$ & 15.39 (3.20) & $15.819(2.68)$ & & \\
\hline
\end{tabular}

The OSCE evaluation checklists were numbered based on the list of names of the participants in alphabetical order, and the students entered the examination room accordingly. The assessors were blinded to both the training and selection process of the students. Each checklist consisted of a different number of items depending on the type of examination and the weight of each item in terms of its importance. The test score for preparing the patient and history taking ranged between $0-1.5$, inspection $0-2$, auscultation $0-2$, percussion $0-4$, palpation $0-7$, and the additional items scored between $0-3.5$. The total score of the checklist ranged between 0-20. The checklist also included a section for the assessors to provide additional comments on the examinations (eg, ethical points) or technical feedback.

The face validity and content validity of the checklists were confirmed by 22 experienced instructors. In terms of the face validity, the impact score of all items was $>1.5$, item-level content validity index (I-CVI) of almost all items was $>0.79$, and scale-level index (S-CVI/Ave) equaled 0.93. Additionally, the internal consistency of the checklists was confirmed (KR$21=0.851$ and alpha $=0.847$ ). To establish the inter-rater reliability of the checklists, 11 nursing students in their fourth year who had successfully passed the physical assessment course were evaluated, and the overall inter-rater kappa correlation coefficient equaled 0.811 .

\section{Phase 2: Training sessions}

The participants were divided into three groups (with one instructor per group), and they all followed a set of 1-hour lectures on the physical examination of the abdomen. The lectures included a PowerPoint presentation and covered the topics of history taking, patient preparation, and physical examination techniques. After these lectures, only the intervention group (45 students) followed an additional training based on the SPs method. In order to have an appropriate student:instructor ratio, the participants were divided into three groups of 15 students (15:1 ratio). The 45-minute SPs training included the physical examination of the abdomen by the instructor (20 minutes), a question and answer session (10 minutes), and the physical examination of the abdomen by the participants (15 minutes).

\section{Phase 3: OSCE evaluations (Post-test and Recall Test)}

The post-test evaluation of both groups was conducted following the OSCE test. A similar evaluation was additionally conducted 2 months later (recall test), during which the students had the opportunity to practice in live clinical settings. 
The level of satisfaction with the SP experience among the intervention group was evaluated using a dedicated four-item viewpoint questionnaire. The questions evaluated the attractiveness and creativity of the SP method, its impact on self-confidence, and the desirability to redeploy SP. The questionnaire was scored using the Likert scale ranging from totally agree to totally disagree. The content validity of the questionnaire was confirmed by nine academic staff members experienced in this field.

\section{Statistical Analysis}

Data were analyzed using the SPSS software (version 16.0). The repeated measurement test was used to compare the total scores of the checklists from the OSCE pre-test, post-test, and recall test.

\section{Ethical Considerations}

This study was approved by the Ethics Committee of Shiraz University of Medical Sciences, Shiraz, Iran (code: IR.
SUMS.REC.1394.65) and was registered in the Iranian Database of Clinical Trials (code: IRCT201505311754N4). Participants were personally informed about the goals of the research, methodology, and confidentiality of any disclosed information. They were also assured that the OSCE scores would not influence their official examination results, and participation had no impact on their academic ranking. A written informed consent was obtained from all the participants.

\section{Results}

All participants were female, and their mean age was $21.99 \pm 1.73$ years. As shown in figure 2, four participants in the control group were excluded in the analysis phase due to being lost to follow-up. The mean pre-test overall score of the control and intervention group was $4.98 \pm 2.17$ and $5.35 \pm 1.77$, respectively. In this regard, no significant difference was observed between the groups. However, there was a significant difference between the mean pre-test and post-test overall

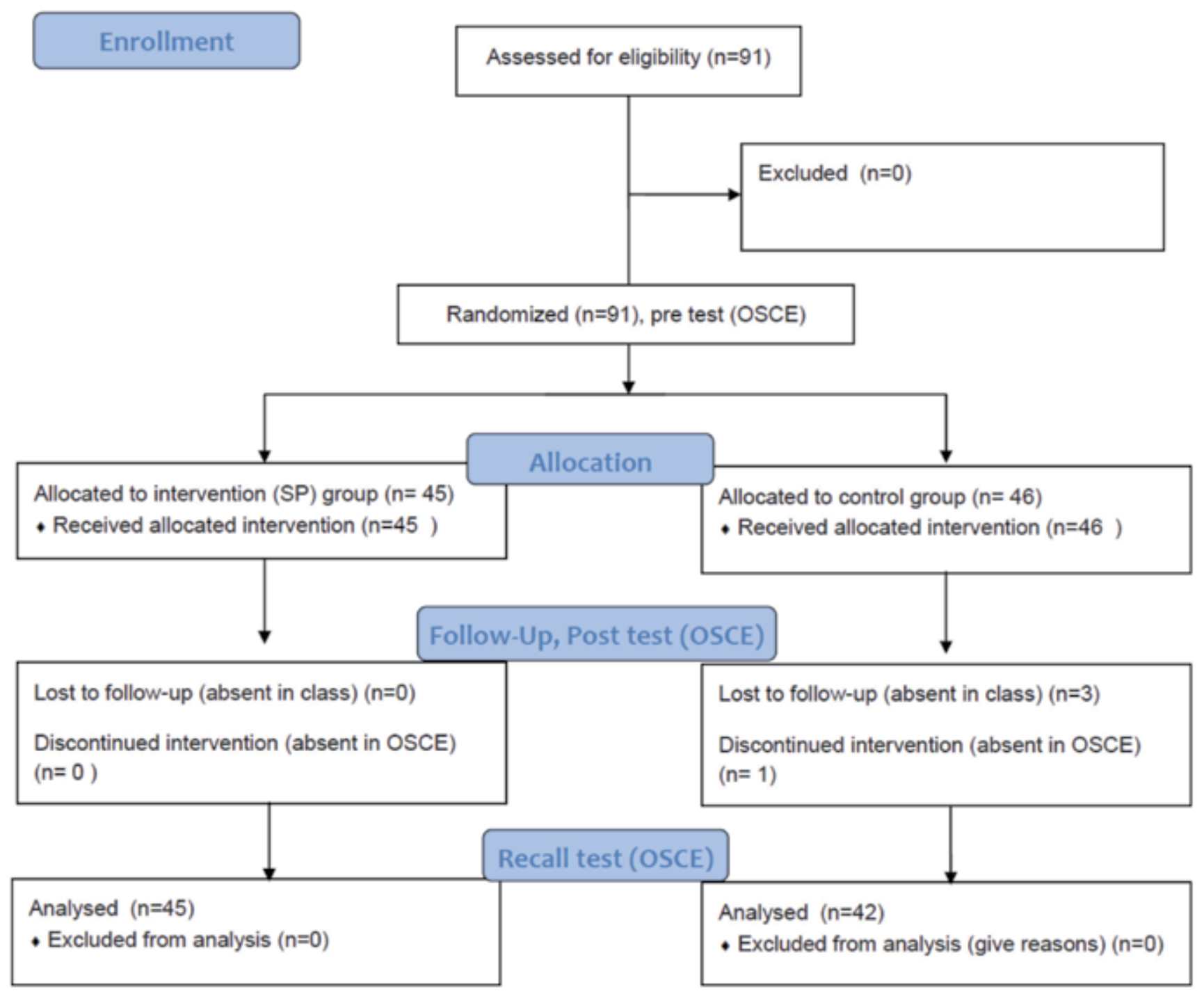

Figure 2. The Consort Flowchart to track participants through randomized clinical trial. 


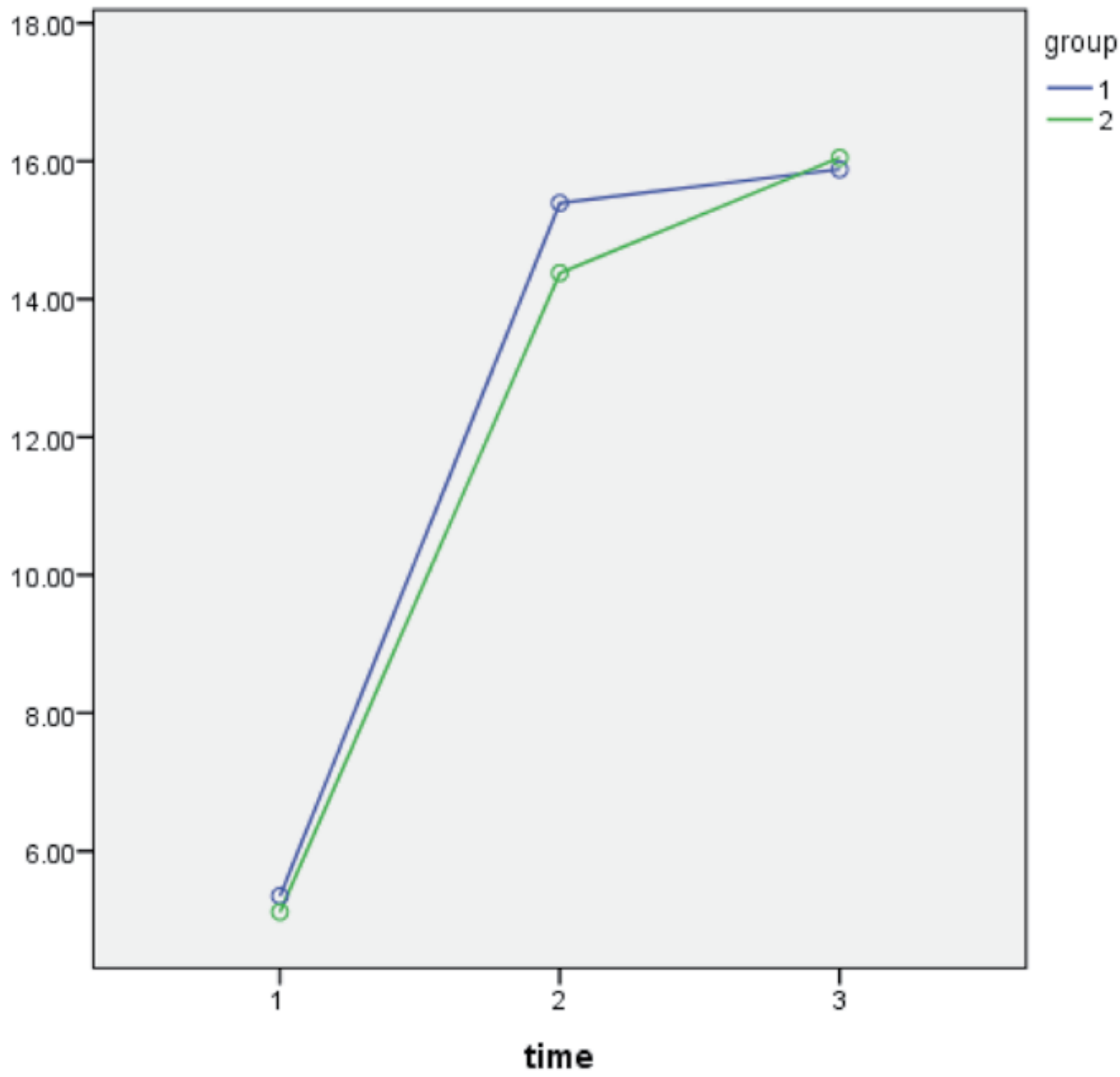

Figure 3. Plot of repeated measurement test comparing overall scores in two groups (1: control group, 2: intervention group)

scores in each group $(P<0.05)$. This implied that the training was effective in both the control and intervention groups. Compared to the control group, the difference in the mean pre-test and post-test scores were higher in the intervention group (4.98 \pm 2.17 and $14.43 \pm 3.93$ in control group vs. $5.35 \pm 1.77$ and $15.39 \pm 3.2$ in experimental group, respectively). However, the difference was not statistically significant $(P>0.05)$. Furthermore, there was no statistically significant difference between the groups in terms of the post-test and recall test scores (table 1).

The results of the repeated measurement test showed a significant difference in the mean pre-test, post-test, and recall test scores within each group in terms of the total score and the six subscales of the checklist $(P<0.001)$. However, there was no significant difference between the two groups $(P>0.05)$, except for addtional examination subscale $(P=0.01)$. The results of interaction effect of time* group also showed no significant difference $(P=0.357)$, which means the change trend of OSCE scores in three tests was similar in both groups (figure 3).

In terms of the outcome measure, the mean difference between the baseline and post-test was calculated using the intention-to-treat (ITT) analysis method. The ITT analysis was performed to determine the comparability of the baseline between the groups by randomization. The results of proprotocol and ITT analyses showed no significant differences between the two groups ( $P=0.208$ and $P=0.17$, respectively). 
To determine the factors affecting the insignificant results, post-hoc power analysis was performed using the $G^{*}$ power statistical software (version 3.0.10). The statistical power of the study equaled 0.635 . This value seemed acceptable considering that all nursing students were recruited in the study with no possibility to increase the sample size. Factors like uncontrolled sources of random error, subject heterogeneity, and measurement error can reduce the study power. Random error occurs due to unknown and unpredictable changes in measuring instruments or changing environmental conditions. On the other hand, measurement errors are related to the tool used in the research. Therefore, another possible cause of limited study power might be the checklist used in the study, even though the reliability of this checklist has been evaluated. In the present study, considering the heterogeneity of the participants and the uncontrollability of the random error, it is possible the low power of the study can be related to the measurement error.

The level of satisfaction with the SP experience among the intervention group was also evaluated. As shown in table 2, the participants indicated that the SP method was attractive and creative, and they would like to attend the course again as well as attending comparable practical courses. Most participants stated that the SP method increased their selfconfidence.

\section{Discussion}

The results of this study revealed that learning occurred in the students of both SP and classroom education groups without any significant difference between their mean scores. In other words, the nursing students' abdominal physical examination skills improved regardless of whether they belonged to the SP or the classroom education group. It implies that the skill of the participants improved regardless of the method-SP or purely lecture-based. This finding was in line with those of some other studies. A previous study compared the SP and lecturing methods in a psychiatric nursing course and reported a significant experience gained by the students using the SP method. However, they also found no significant difference between lecturing and SP methods in terms of mental health knowledge and interpersonal skills. ${ }^{52}$ Inadequate explanation and limited discussion time could have been the main reason for such insignificant results in the present study. Therefore, we strongly recommend allowing for more discussion and debriefing sessions.

We found that the SP method had a positive impact on the performance of the students in physical assessment skills in both SP and classroom education group. Comparable studies also indicated the benefits of the SP method on the performance of the students..$^{52-52}$ Kurz et al ${ }^{56}$ reported that nursing students who practiced health assessment skills using OSCE and SP scored higher in practical examination and satisfaction. Another study showed that nursing students who were taught physical assessment skills using SP in well-equipped laboratories gained significantly higher performance scores compared to the control group. ${ }^{53}$

However, contradictory findings have been reported in some other studies. Saboori et $\mathrm{al}^{43}$ conducted the only quasiexperimental study in Iran on history-taking skills using the SP method. They showed no significant differences between the control and intervention groups regarding history taking, although the mean score of the intervention group was higher. Hence, they only used post-test data, whereas our results were based on a comparison between the pre-test and post-test data (ie, the main strength of our study). Swanson et $\mathrm{al}^{57}$ also reported no significant difference between the SP method and the case-based learning approach with respect to knowledge acquisition, satisfaction, and self-efficacy. In contrast, another study reported that nursing students trained by high-fidelity simulation (HFS) performed significantly better in respiratory health assessment in comparison with those trained by SP or community-volunteer methods. ${ }^{58}$ Nevertheless, the learners' satisfaction was significantly lower in HFS and no significant differences were observed among the three methods regarding self-efficacy. ${ }^{58}$

The inconsistency of the above-mentioned results could be the study power. While in most studies the focus is on achieving significant statistical results, some writers believe that the investigators have to consider study power to ensure they are able to reject the null hypothesis that deserves rejection. Unfortunately, in most studies investigating the impact of using SP on learning and skills, the researchers have

Table 2. The students' satisfaction with the SP method

\begin{tabular}{|c|c|c|c|c|c|c|}
\hline \multirow[b]{2}{*}{ Item } & \multirow[b]{2}{*}{$\begin{array}{l}\text { No. of } \\
\text { responses }\end{array}$} & \multicolumn{5}{|c|}{ No (\%) } \\
\hline & & $\begin{array}{l}\text { Strongly } \\
\text { agree }\end{array}$ & Agree & No comment & Disagree & $\begin{array}{l}\text { Strongly } \\
\text { disagree }\end{array}$ \\
\hline This class was attractive & 48 & $23(46.94)$ & $21(42.86)$ & $3(6.25)$ & $0(0)$ & $1(2.08)$ \\
\hline $\begin{array}{l}\text { I would like more courses to } \\
\text { be taught by this method }\end{array}$ & 50 & $26(53.06)$ & $14(28.57)$ & $4(8)$ & $0(0)$ & $0(0)$ \\
\hline $\begin{array}{l}\text { I enjoyed the creativity of } \\
\text { SP training }\end{array}$ & 50 & $22(44.9)$ & $19(38.77)$ & $9(18)$ & $0(0)$ & $0(0)$ \\
\hline $\begin{array}{l}\text { I think practicing these skills } \\
\text { in skill lab on SP promoted } \\
\text { my self-confidence }\end{array}$ & 50 & $22(44.9)$ & $22(44.9)$ & $3(6)$ & $2(4)$ & $1(2)$ \\
\hline
\end{tabular}


not provided information about their study power. Therefore, merely relying on significant or non-significant statistical difference between traditional and SP methods might hide the real clinical significance of such results. Overemphasis on significant results could lead to indistinguishing the statistical significance of a result from its scientific significance. To achieve evidence-based practice as the basis of clinical decision making, it is essential for researcher to report their study powers.

The findings of the present study indicate that the students taught by the SP method had a higher level of satisfaction. The students stated that this method was more attractive and enjoyable than the lecture-based education, and they would like to attend more of such trainings. A similar level of student's satisfaction with the SP method has been reported in other studies..$^{52,55,59}$

The main strength of the present study is that our findings were based on a comparison between the pre-test, post-test, and recall test results. This approach is a significant improvement compared to similar Iranian studies that only used post-test data. ${ }^{43}$ Moreover, all psychometric properties of the checklists were assessed, which is a strength compared to similar studies. An additional strength is the effort made to minimize observer bias. As mentioned earlier, the assessors were blinded to both the training and the selection process of the participants. Considering scarce studies on this topic in Iran, the present study should be seen as a pilot study based on which the study design could be adopted toward large-scale research with a larger sample size.

Empowering Iranian nursing students and nurses with the knowledge and skills needed for qualified care is essential. ${ }^{60}$ However, this research should be considered a pilot study in the area of using SP in nursing education in Iran.

The main limitation of the present study was the low sample size and the recruitment of participates from a single center. In turn, it did not allow generalizability of the findings. We also did not investigate the effect of confounders such as anxiety and stress on the OSCE results, especially since the test was the first such experience for the students. Indeed, the grade point average (GPA) was not matched, which could affect the results as a confounder. We also did not ask the participants in the control group to respond to the satisfaction questionnaire, which prevented us from comparing the data with the results from the intervention group.

It is recommended that future studies on physical assessment education should include (i) assessment of the nursing students in live clinical settings after graduation, (ii) determination of the role of human simulators in knowledge acquisition and improving critical thinking skills and competence, (iii) collecting students' demographic information such as employment status, anxiety and stress level regarding OSCE, and (iv) GPA in the current and previous semesters that might contribute to knowledge acquisition and learning outcomes.

\section{Conclusion}

The present study addressed the topic of SP from a contextual angle and its value for training Iranian nursing students. Our study demonstrated that the SP method is as effective as the lecture-based education method in performing the physical examination. It also showed that this method was more attractive and enjoyable to the students, which could increase their learning motivation. The present pilot study could be extended to cover training on physical examination of other human organs. Furthermore, other teaching courses (eg, clinical interviews, emergency nursing, and fundamental nursing) could also benefit from the SP method. Further nationwide studies are required to determine the effectiveness of the SP method in Iranian nursing education.

\section{Acknowledgment}

This manuscript was extracted from a proposal financially supported by the Vice-Chancellor for Research Affairs of Shiraz University of Medical Sciences, Shiraz, Iran (Grant No. 92-01-21-6599). The authors would like to thank Center for Development of Clinical Research of Namazee Hospital for statistical analysis of the data. They are also grateful for Ms. A. Keivanshekouh at the Research Improvement Center of Shiraz University of Medical Sciences for improving the use of English in the manuscript. Thanks also go to the experts who assessed the validity, the assessors who cooperated in measuring the reliability, and the students who participated in some stages of the study.

\section{References}

1. DeLaune S, Ladner P. Fundamentals of nursing. Boston, MA: Cengage Learning; 2010.

2. Potter PA, Perry AG, Stockert P, Hall A. Fundamentals of nursing. 9th ed. London, UK: Elsevier Health Sciences; 2013.

3. Jarvis C. Physical Examination and Health Assessment. 7th ed. Philadelphia: Elsevier/Saunders; 2012.

4. Giddens JF, Eddy L. A survey of physical examination skills taught in undergraduate nursing programs: are we teaching too much? J Nurs Educ. 2009;48(1):24-29.

5. Giddens JF. A Survey of physical assessment techniques performed by RNs: lessons for nursing education. J Nurs Educ. 2007;46(2):83-87.

6. Birks M, Cant R, James A, Chung C, Davis J. The use of physical assessment skills by registered nurses in Australia: Issues for nursing education. Collegian. 2013;20(1):27-33.

7. Osborne S, Douglas C, Reid C, Jones L, Gardner G; RBWH Patient Assessment Research Council. The primacy of vital signs - Acute care nurses' and midwives' use of physical assessment skills: A cross sectional study. Int J Nurs Stud. 2015;52(5):951-962.

8. Secrest JA, Norwood BR, Dumont PM. Physical assessment skills: a descriptive study of what is taught and what is practiced. J Prof Nurs. 2005;21(2):114-118.

9. Wearn AM, Bhoopatkar H, Mathew TK, Stewart L. Exploration of the attitudes of nursing students to peer physical examination and physical examination of patients. Nurse Educ Today. 2013:33(8):884-888. PMID: 22986173. 
10. Farsi Z, Dehghan-Nayeri N, Negarandeh R, Broomand S. Nursing profession in Iran: An overview of opportunities and challenges. Jpn J Nurs Sci. 2010;7(1):9-18.

11. Aebersold M, Tschannen D, Bathish M. Innovative simulation strategies in education. Nurs Res Pract. 2012;2012:1-7.

12. Benner P, Sutphen M, Leonard VL. Educating nurses: A call for radical transformation. San Francisco, CA: Jossey-Bass; 2009.

13. Forsberg I, Swartwout K, Murphy M, Danko K, Delaney KR. Nurse practitioner education: greater demand, reduced training opportunities. J Am Assoc Nurse Pract. 2015;27(2):66-71.

14. Hayden KJ, Smiley AR, Alexander M, Kardon-Edgren S, Jeffries PR. The NCSBN national simulation study: a longitudinal, randomized, controlled study replacing clinical hours with simulation in prelicensure nursing education. Journal of Nursing Regulation. 2014;5(Suppl 2).

15. Jeffries PR, Beach M, Decker S, et al. Multi-center development and testing of a simulation-based cardiovascular assessment curriculum for advanced practice nurses. Nurs Educ Perspect. 2011;32(5):316-322.

16. Karnath B, Thornton W, Frye AW. Teaching and testing physical examination skills without the use of patients. Acad Med. 2002;77(7):753.

17. Lesa R, Dixon A. Physical assessment: implications for nurse educators and nursing practice. Int Nurs Rev. 2007;54(2):166172.

18. Reinhardt AC, Mullins IL, De Blieck C, Schultz P. IV insertion simulation: Confidence, skill, and performance. Clin Simul Nurs. 2012;8(5):e157-e167.

19. Weatherspoon DL, Phillips K, Wyatt TH. Effect of Electronic Interactive Simulation on Senior Bachelor of Science in Nursing Students' Critical Thinking and Clinical Judgment Skills. Clin Simul Nurs. 2015;11(2):126-133.

20. Lin ECL, Chen SL, Chao SY, Chen YC. Using standardized patient with immediate feedback and group discussion to teach interpersonal and communication skills to advanced practice nursing students. Nurse Educ Today. 2013;33(6):677683.

21. Ryan CA, Walshe N, Gaffney R, Shanks A, Burgoyne L, Wiskin $\mathrm{CM}$. Using standardized patients to assess communication skills in medical and nursing Students. BMC Med Educ. 2010;10(1):24.

22. Rourke L, Schmidt M, Garga N. Theory-based research of high fidelity simulation use in nursing education: a review of the literature. Int J Nurs Educ Scholarsh. 2010;7(1):e11.

23. Yuan HB, Williams BA, Fang JB, Ye QH. A systematic review of selected evidence on improving knowledge and skills through high-fidelity simulation. Nurse Educ Today. 2012;32(3):294-298.

24. Norman G, Dore K, Grierson L. The minimal relationship between simulation fidelity and transfer of learning. Med Educ. 2012;46(7):636-647.

25. Robinson-Smith G, Bradley PK, Meakim C. Evaluating the use of standardized patients in undergraduate psychiatric nursing experiences. Clin Simul Nurs. 2009;5(6):e203-e211.

26. Bokken L, Rethans JJ, Jöbsis Q, Duvivier R, Scherpbier A, van der Vleuten $\mathrm{C}$. Instructiveness of real patients and simulated patients in undergraduate medical education: a randomized experiment. Acad Med. 2010;85(1):148-154.

27. Jha V, Setna Z, Al-Hity A, Quinton ND, Roberts TE. Patient involvement in teaching and assessing intimate examination skills: a systematic review. Med Educ. 2010;44(4):347-357.

28. Nestel D, Clark S, Tabak D, et al. Defining responsibilities of simulated patients in medical education. Simulation in Healthcare: The Journal of the Society for Simulation in Healthcare. 2010;5(3):161-168.
29. Schram AP, Mudd S. Implementing Standardized Patients Within Simulation in a Nurse Practitioner Program. Clin Simul Nurs. 2015;11(4):208-213.

30. Wallace P. Following the threads of an innovation: the history of standardized patients in medical education. Caduceus 1997; 13:5-28.

31. Jeffries PR. Simulation in nursing education: from conceptualization to evaluation. 2nd ed. New York: National League for Nursing; 2012.

32. Anderson M, Holmes TL, LeFlore JL, Nelson KA, Jenkins T. Standardized patients in educating student nurses: one school's experience. Clin Simul Nurs. 2010;6(2):e61-e66.

33. Barnett GV, Hollister L, Hall S. Use of the standardized patient to clarify interdisciplinary team roles. Clin Simul Nurs. 2011;7(5):e169-e173.

34. Farmer SR. Impact of standardized patient simulation on nursing student anxiety levels during initial clinical encounters with psychiatric clients. Dissertation: Northern Kentucky University; 2015.

35. Bruce SA, Scherer YK, Curran CC, Urschel DM, Erdley S, Ball LS. A collaborative exercise between graduate and undergraduate nursing students using a computer-assisted simulator in a mock cardiac arrest. Nurs Educ Perspect. 2009;30(1):22-27.

36. Shin S, Park JH, Kim JH. Effectiveness of patient simulation in nursing education: Meta-analysis. Nurse Educ Today. 2015;35(1):176-182.

37. Shawler C. Standardized patients: a creative teaching strategy for psychiatric-mental health nurse practitioner students. J Nurs Educ. 2008;47(11):528-531.

38. Lee CA, Chang A, Chou CL, Boscardin C, Hauer KE. Standardized patient-narrated web-based learning modules improve students' communication skills on a high-stakes clinical skills examination. J Gen Intern Med. 2011;26(11):1374-1377.

39. Shawler C. Palliative and end-of-life care: using a standardized patient family for gerontological nurse practitioner students. Nurs Educ Perspect. 2011;32(3):168-172.

40. May W, Park JH, Lee JP. A ten-year review of the literature on the use of standardized patients in teaching and learning: 1996-2005. Med Teach. 2009;31(6):487-492.

41. Tung HH, Tsay SL, Wang TJ. Current practice of nurse practitioner in Taiwan. Formosan Journal of Medicine. 2009;14(3):264-271.

42. Comer SK. Patient care simulations: role playing to enhance clinical understanding. Nurs Educ Perspect. 2005;26(6):357361.

43. Saboori M, Jafari F, Monajemi A. [article in Persian] The effect of employing standardized patient on history taking skills of medical students. Iranian Journal of Medical Education 2010;10(3):276-283.

44. Taghva A, Mir-sepassi GR, Sadeghi M, Panaghi L, Ghalebandi M. [article in Persian] Are Standardized Patients Able to Rate Performance of Psychiatric Residents in the Objective Structured Clinical Examination? Iranian Journal of Psychiatry \& Clinical Psychology 2007;13(1):29-33.

45. Nasrabadi AN, Lipson JG, Emami A. Professional nursing in Iran: An overview of its historical and sociocultural framework. J Prof Nurs. 2004;20(6):396-402.

46. Oskouei F, Nejatian A, Parvizy S. Registration/Licensure: Essential Need of Nursing Regulation in Iran. International Journal of Medical Research \& Health Sciences. 2016;5:423428.

47. Bickley L. Bates' guide to physical examination and history taking. 10th ed. Philadelphia, PA: Lippincott Williams \& Wilkins; 2012. 
48. Hurley KF. OSCE and clinical skills handbook. 2nd ed.) Philadelphia, PA: Elsevier/Saunders; 2011.

49. Jarvis C, Browne AJ, MacDonald-Jenkins J, Luctkar-Flude M. Physical examination \& health assessment. Toronto: Elsevier; 2009.

50. Jarvis C. Physical examination and health assessment. 5th ed. Philadelphia, PA: Saunders; 2011.

51. Seidel MH, Ball WJ, Dains EJ, Flynn JA, Solomon BS, Steward RW. Mosby's guide to physical examination. 7th ed. Frisco, TX: Mosby; 2011.

52. Becker KL, Rose LE, Berg JB, Park H, Shatzer JH. The teaching effectiveness of standardized patients. J Nurs Educ. 2006;45(4):103-111.

53. Bornais JAK, Raiger JE, Krahn RE, El-Masri MM. Evaluating undergraduate nursing students' learning using standardized patients. J Prof Nurs. 2012;28(5):291-296.

54. Cohen AG, Kitai E, David SB, Ziv A. Standardized patientbased simulation training as a tool to improve the management of chronic disease. Simulation in Healthcare: The Journal of the Society for Simulation in Healthcare. 2014;9(1):40-47.

55. Kim-Godwin YS, Livsey KR, Ezzell D, Highsmith C. Home visit simulation using a standardized patient. Clin Simul Nurs. 2013;9(2):e55-e61.

56. Kurz JM, Mahoney K, Martin-Plank L, Lidicker J. Objective structured clinical examination and advanced practice nursing students. J Prof Nurs. 2009;25(3):186-191.

57. Swanson EA, Nicholson AC, Boese TA, Cram E, Stineman AM, Tew K. Comparison of selected teaching strategies incorporating simulation and student outcomes. Clin Simul Nurs. 2011;7(3):e81-e90.

58. Luctkar-Flude M, Wilson-Keates B, Larocque M. Evaluating high-fidelity human simulators and standardized patients in an undergraduate nursing health assessment course. Nurse Educ Today. 2012;32(4):448-452.

59. Richardson L, Resick L, Leonardo M, Pearsall C. Undergraduate students as standardized patients to assess advanced practice nursing student competencies. Nurse Educ. 2009;34(1):12-16.

60. Adib Hajbaghery M, Salsali M. A model for empowerment of nursing in Iran. BMC Health Serv Res. 2005;5(1):24.

\section{Author Affiliations}

Azita Jaberi, PhD*; Marzieh Momennasab, PhD†

*Community Based Psychiatric Care Research Center,

School of Nursing and Midwifery, Shiraz University of

Medical Sciences, Shiraz, Iran

†Department of Nursing, School of Nursing and Midwifery,

Shiraz University of Medical Sciences, Shiraz, Iran 